\title{
Anterior Multiple Supernumerary Teeth in a Non Syndromic Child Managed With Gropers Appliance a Case Report
}

Surg Capt DMM Chengappa, MDS ${ }^{1 *}$, Surg Cdr Akshai Kannan MDS $^{2}$, Col Prasanna Kumar, MDS ${ }^{3}$, Maj Ashish Bhalla, MDS $^{4}$, Dr. P Praveen, MDS ${ }^{5}$, Dr. A Anantharaj, MDS ${ }^{6}$

\author{
${ }^{1}$ Graded Specialist (Pedodontics), INHS Sanjivani, Naval Base, Kochi, Kerala - 682004, India \\ ${ }^{2}$ Graded Specialist (Orthodontics), INHS Sanjivani, Naval Base, Kochi, Kerala - 682004, India \\ ${ }^{3}$ Professor (Orthodontics), Dept of Dental Surgery, Armed Forces Medical College, Pune - 411 040, India \\ ${ }^{4}$ Graded Specialist (Pedodontics), Army Dental Centre (R\&R), Delhi Cantt, New Delhi - 110 010, India \\ ${ }^{5}$ Professor, Dept of Pedodontics and Preventive Dentistry, DAPM RV Dental College, Bangalore, India \\ ${ }^{6}$ Professor \& HOD, Dept of Pedodontics and Preventive Dentistry, DAPM RV Dental College, Bangalore, India
}

DOI: $10.36347 /$ sjds.2020.v07i03.004

| Received: 09.03.2020 | Accepted: 19.03.2020 | Published: 27.03.2020

*Corresponding author: DMM Chengappa

Abstract

Case Report

Aim: The aim of this article is to present a case of multiple supernumerary teeth in the anterior maxillary segment in a non-syndromic child. Background: A supernumerary tooth is an additional tooth over and above the normal number found in the dentition. The prevalence of supernumerary teeth in Indian population is around $1.2 \%$, with greater frequency in males which was $1.49 \%$ and in females the frequency was $0.85 \%$. Case Description: A 6 yr old child came to our institute with his parents who were worried about the appearance of his upper front teeth. On examination it was seen that the child had sharp peg shaped central incisors. Radiographic examination revealed multiple supernumerary teeth in the anterior maxillary segment. The family's medical history was non-contributory. These supernumerary teeth were obstructing the eruption pathway of the permanent incisors and therefore it was decided to extract them so as to allow normal eruption of permanent teeth. Summary: It is uncommon to find multiple supernumerary teeth in individuals with no other associated diseases or syndromes. This case report presents a case of a non-syndromic child with multiple supplemental supernumerary teeth in the maxillary anterior segment managed with surgical excision and fixed aesthetic rehabilitation. Clinical Significance: An early diagnosis is key to the successful management of these anomalies along with a good radiographic investigation and institution of a treatment plan for their early removal to prevent deleterious effects on the permanent dentition.

Keywords: Hyperdontia, Multiple supernumerary teeth, Non-syndromic, supernumerary teeth, Aesthetic management. Copyright @ 2020: This is an open-access article distributed under the terms of the Creative Commons Attribution license which permits unrestricted use, distribution, and reproduction in any medium for non-commercial use (NonCommercial, or CC-BY-NC) provided the original author and source are credited.

\section{BACKGROUND}

The occurrence of multiple supernumerary teeth is also known as Hyperdontia. This situation is characterized by the occurrence of excess number of teeth both erupted and non-erupted. Hyperdontia is a condition that can occur in both deciduous and permanent dentition [1]. The incidence of Hyperdontia across the world has been shown to be as high as $3 \%$ with males being affected twice as frequently as females. $^{2}$ In Indian population supernumerary teeth have been found to have an incidence of around $1.2 \%$ of the population [3]. The most common site of occurrence of supernumerary teeth is in the maxilla with it accounting for about $90 \%$ to $98 \%$ of all such occurrences. The majority of these supernumerary teeth are in the form of mesiodens found in the palatal midline and frequently these teeth are located palatal to the maxillary central incisors [4]. These anomalies of tooth number occur more commonly in people with a hereditary disposition or those with syndromic conditions such as Cleidocranial Dysplasia, Gardner's Syndrome and Down's syndrome. These supernumerary teeth can cause various complications; most common among them is dental malposition [5]. This article presents a case report of a non-syndromic male child with multiple supplemental supernumerary teeth in the maxillary anterior region.

\section{CASE DESCRIPTION}

A six year old male child was brought to our institute by his parents with the chief complaint of improperly formed teeth. The parents gave a history of exfoliation of the deciduous central incisors about two years ago and eruption of sharp unsightly peg shaped 
incisors (Fig 1). The parents were apprehensive as they thought that these were his permanent teeth as his lower permanent incisors had also erupted. A routine Intra Oral Periapical Radiograph was done to rule out presence of any supernumerary tooth. The radiograph showed presence of multiple supernumerary teeth but it was difficult to exactly point out the number of extra teeth present because of the atypical shape of the teeth present and their proximity to the erupting permanent incisor teeth. Therefore an occlusal radiograph was taken which revealed the presence of at least three supernumerary teeth in addition to the erupted peg shaped supernumeraries central incisors (Fig 2). A through history revealed no familial presence of the condition.

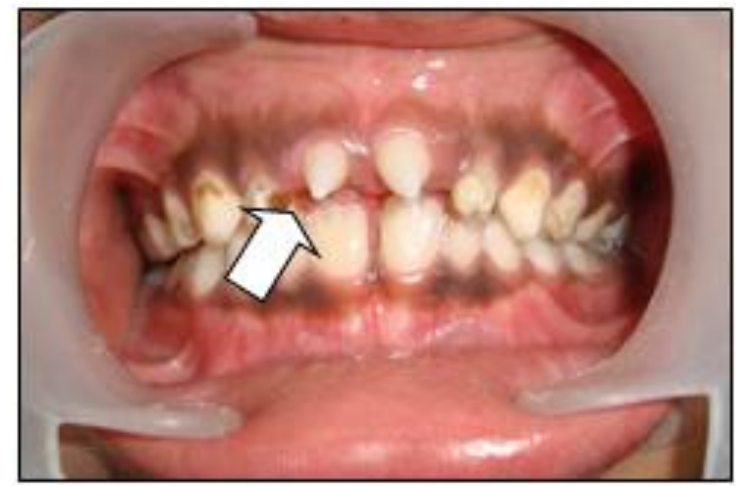

Fig-1: Intra oral view of the child showing peg shaped supernumeraries (arrow)

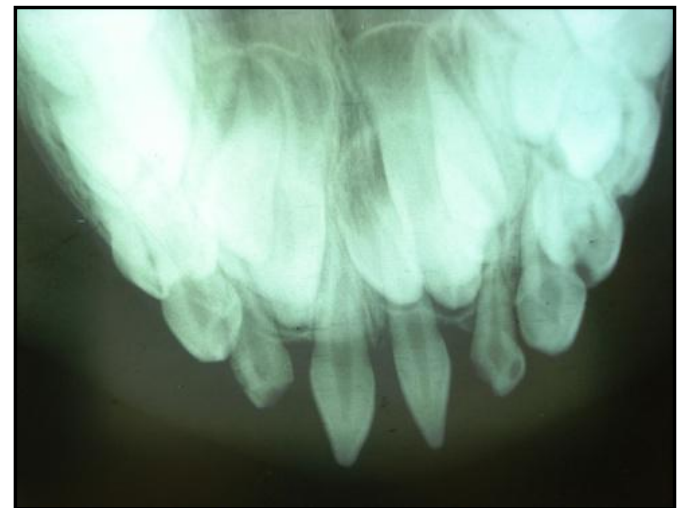

Fig-2: Occlusal radiograph showing multiple supernumerary teeth

As these supernumerary teeth were in the path of eruption of the permanent central incisors the parent was informed of the need to extract these teeth. The child also had multiple carious teeth was very apprehensive and was unwilling to get any treatment done. He was classified under the Frankls behaviour rating scale and given a score of 2 which indicated negative behaviour pattern. As the child also had other teeth which required extensive repair with placement of stainless steel crowns and keeping his behavioural condition in mind it was decided to do the procedure under GA. a CT scan was done prior to the procedure to determine the exact location of the supernumerary teeth in relation to the permanent teeth (Fig 3). The procedure was explained to the parent and an informed consent was taken. The child was intubated and administered General Anaesthesia. It was decided to complete all restorative work first by placement of Stainless Steel Crowns on $54,74,75 \& 84$ and GIC restoration on 63,64 .
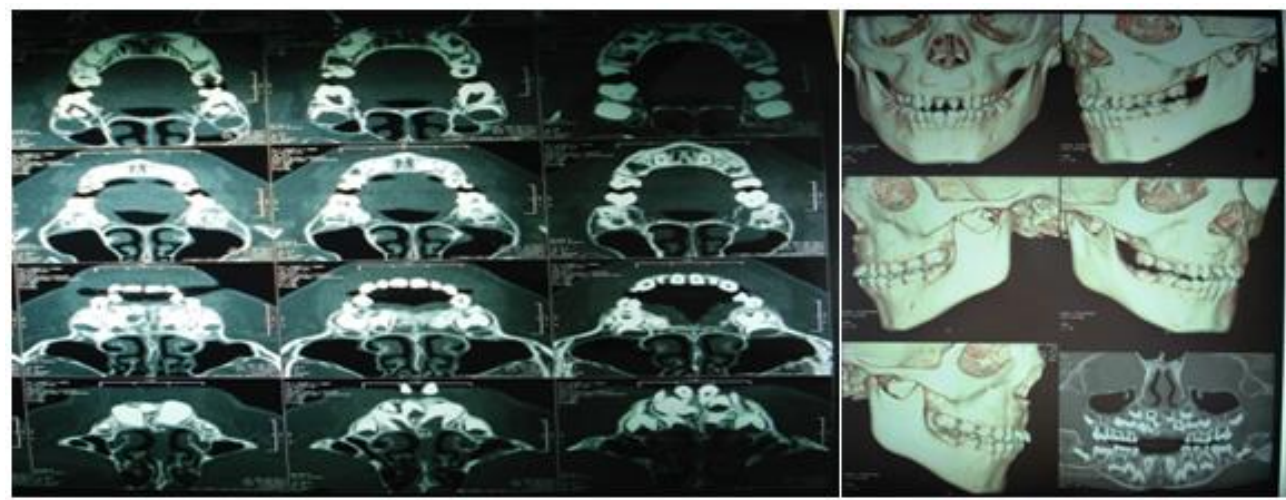

Fig-3: CT Scan images revealing the exact no and location of the supernumerary teeth

The surgical treatment was commenced with extraction of the peg shaped supernumerary teeth after administration of local anaesthetic containing $2 \%$ lignocaine with 1:1,00,000 adrenaline. A buccal flap was raised and bone was removed using a slow speed bur alongwith copious amount of saline irrigation. This revealed the presence of three tuberculate supernumerary teeth which were carefully extracted without disturbing the permanent tooth buds(Fig 4,5). The deciduous lateral incisors 52,62 also had to be extracted as they were mobile due to lack of sound supporting bone structure.The margins of bone were smoothened prior to closure of the wound. The flap was then repositioned and sutured with $3 / 0$ silk sutures(Fig $6)$. The post surgical recovery was uneventful and the child was given a cover of antibiotics and analgesics. The suture removal was done after one week and impressions were made for replacement of missing teeth. 


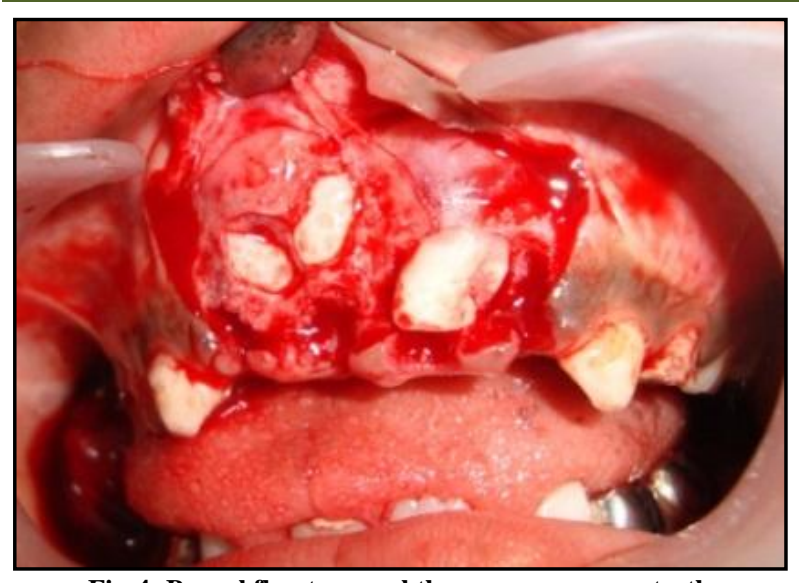

Fig-4: Buccal flap to reveal the supernumerary teeth

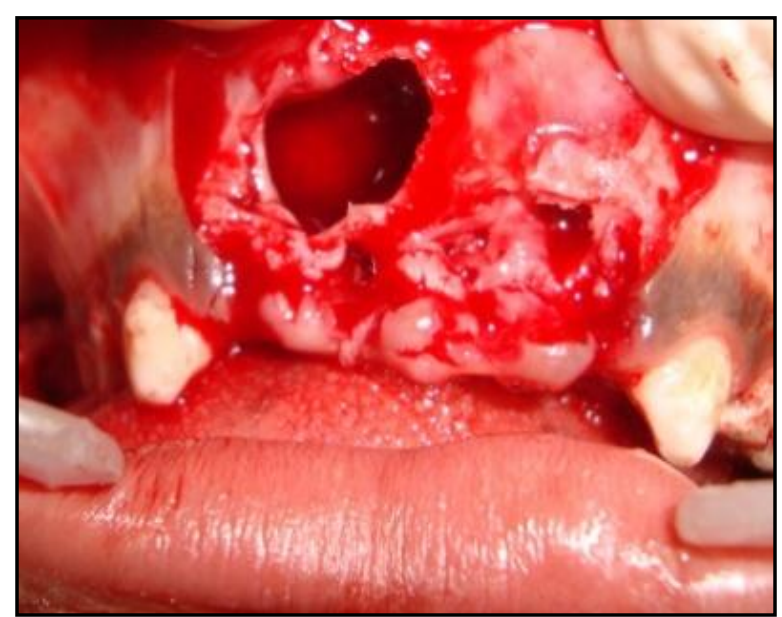

Fig-5: Post extraction socket

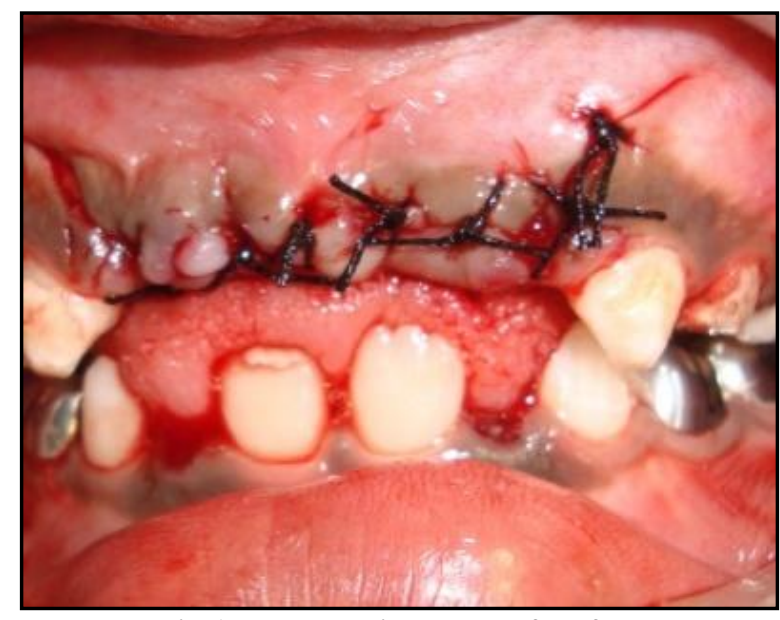

Fig-6: Post extraction closure of the flap

The child was given a fixed functional space maintainer (Gropers Appliance) to provide aesthetics and prevent development of deleterious oral habits and speech deficits (Fig 8, 9). He was kept on regular follow up to check for eruption status of his permanent central incisors.

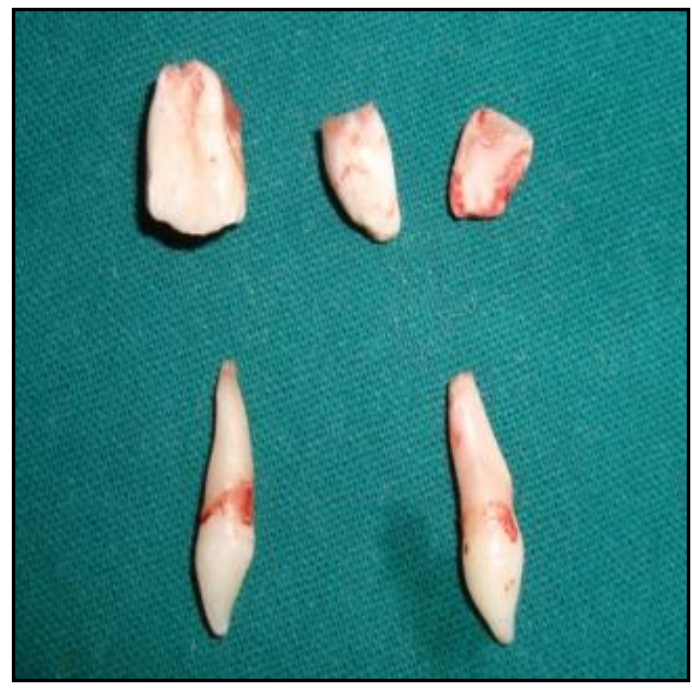

Fig-7: Extracted supernumerary teeth

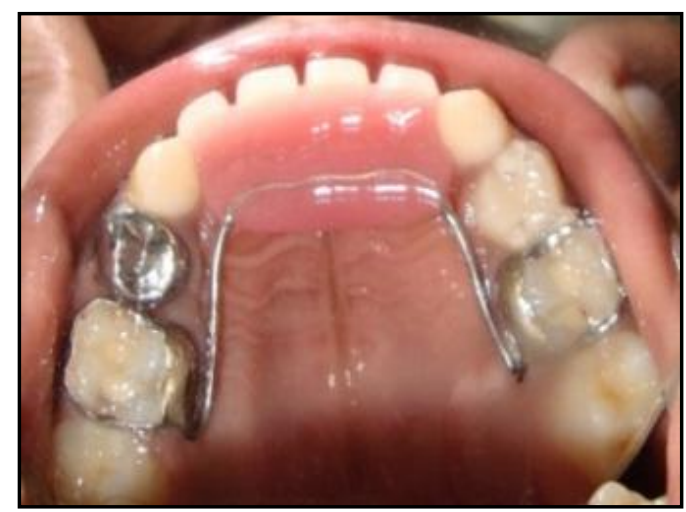

Fig-8: Occlusal view of the functional space maintainer

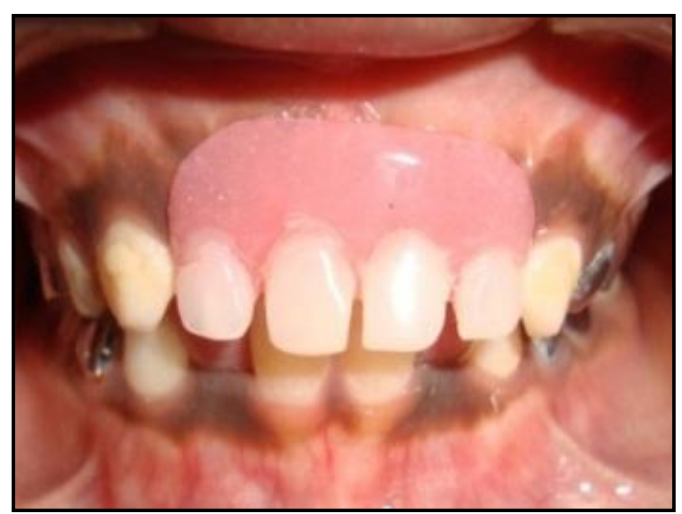

Fig-9: Frontal view of the functional space maintainer

\section{DISCUSSION}

Supernumerary teeth are developmental anomalies which have been debated to have multiple aetiologies $[1,13]$. There are many theories which have delved into the causes of their occurrence, including the: phylogenetic theory, dichotomy theory, hyperactive dental lamina or a combination of genetic and environmental factors. The phylogenetic theory states that hyperdontia could be the result of a reversional phenomenon or atavism (with evolutionary throwback). The dichotomy theory suggests that a supernumerary tooth may have developed from the complete bifurcation of the tooth bud into 2 equal or different- 
sized parts, leading to formation of 2 teeth of equal size or 1 tooth of normal size and 1 dysmorphic tooth, respectively. The theory of hyperactive dental lamina is the most accepted cause for the presence of supernumerary teeth where supernumerary teeth are formed as a consequence of some local, independent, and conditioned hyperactivity of the dental lamina. The remnants of this dental lamina can persist as epithelial pearls or islands within the jaw and on stimulation can result in formation of supernumerary tooth [6-9]. These tooth can result in complications such as impaction or ectopic eruption, dentigerous cyst formation, pericoronal space ossification and crown resorption. This necessitates their early extraction to avoid detrimental effects on the erupting permanent successors [10].

\section{CONCLUSION}

The presence of multiple supernumerary teeth is more often than not associated with syndromes; however in rare instances it can be present with no such association.

\section{CLINICAL SIGNIFICANCE}

The most important factor in relation to these anomalies is the early diagnosis of the condition, its radiographic investigation and institution of a treatment plan for their early removal to prevent deleterious effects on the permanent dentition.

\section{ACKNOWLEDGMENT}

The authors would like to acknowledge all the help and support provided by the staff of Dept of Pediatrics and Preventive Dentistry DAPM RV Dental College, Bangalore.

\section{REFERENCES}

1. Smith JD. Hyperdontia : report of a case . J Am Dent Assoc. 1969: 79: $1191-2$.

2. Primosh RE: Anterior supernumerary teethassessment and surgical intervention in children, $\mathrm{J}$ Pediatr Dent 3:204-215, 1981.
3. Brook AH. A unifying etiological explanation for anomalies of human tooth number and size. Archs Oral Biol 1984: 29: 373-8.

4. Von Arx T: Anterior supernumerary teeth: a clinical and radiographic study, Aust Dent $\mathbf{J}$ 37:189-195,1992.

5. Mason C, Rule DC. Midline supernumeraries: a family affair. Dent Update 1995; 22(1):34-5.

6. Liu JF. Characteristics of premaxillary supernumerary teeth: A survey of 112 cases. J Dent Child 1995: 62: 262-5.

7. Mason C, Rule DC, Hopper C. Multiple supernumeraries: the importance of clinical and radiographic follow-up. Dentomaxillofac Radiol 1996; 25: 109-113.

8. Stellzig A, Basdra EK, Komposch G. Mesiodentes: Incidence, morphology, etiology. J Orofac Orthop 1997; 58(3):144-53.

9. Mahabob MN, Anbuselvan GJ, Kumar BS, Raja S, Kothari S: Prevalence rate of supernumerary teeth among non-syndromic South Indian population: An analysis, J Pharm Bioallied Sci. 2012 Aug;4(Suppl 2):S373-5.

10. Casamassimo PS, McTigue DJ, Fields HW, Nowak AJ: Pediatric Dentistry Infancy through Adolescence $5^{\text {th }}$ edition, St Louis, 2013, Saunders.

11. Nirmala SV, Chilamakuri S, Thirupati SP. Bilatera 1 Double Primary Teeth Associated with Multiple Odontogenic Anomalies i n Permanent Dentition: A Case Report. EC Paediatrics. 2015;1:54-61

12. Swamy DF, Barretto ES, Dessai SS, Manuela K, D'Souza KM, Alex SA. The talon cusp anomalyReview of the literature and treatment options. J Appl Dent Med Scienc. 2017;3:2.

13. Koch G, Thesleff I, Kreiborg S. Tooth development and disturbances in number and shape of teeth. InPediatric Dentistry: A Clinical Approach. 2017 Jan 4. Wiley-Blackwell, Hoboken, NJ, 28-39. 